\title{
Comparison of some clinical and histological features of colorectal carcinoma occurring in patients below and above 40 years
}

\author{
M V C de Silva', M S Fernando² and D Fernando ${ }^{3}$ \\ (Index words: Dukes staging, signs and symptoms, histology)
}

\begin{abstract}
Objective To determine the clinicopathological features of colorectal malignancies in Sri Lankan patients aged $\mathbf{4 0}$ years or younger, and to compare them with those of older patients.

Methods The clinicopathological features of 60 colorectal malignancies which occurred in patients aged $\mathbf{4 0}$ years or younger were compared with 245 malignant colorectal tumours in older patients. These tumours had been diagnosed at a University Department of Pathology over 15 years.

Results $19.7 \%$ of colorectal malignancies occurred in patients aged 40 years or younger. (Male: Female ratio = 1.6:1). The mean duration from onset of symptoms to diagnosis was 4.2 months. There was no statistically significant difference between young and old patients in the presenting symptoms, site of tumour and Dukes' staging of colorectal malignancies. A statistically significant proportion of tumours in young patients was mucoid (13.3\%) or signet ring cell (5\%) type. $3.3 \%$ of young patients with colorectal carcinoma gave a family history of similar malignancy. A history of predisposing conditions (ulcerative colitis) was present in 3.3\% of young patients.
\end{abstract}

Conclusions The clinical presentation of colorectal malignancies in Sri Lankan patients below 40 years of age does not differ from that in older patients. Mucoid and signet ring cell carcinomas are commoner in the young.

\section{Introduction}

Colorectal carcinoma is the third most common malignancy world-wide (1). It is often regarded as a disease of the elderly with a peak incidence in the $6^{\text {th }}$ and $7^{\text {th }}$ decades $(2,3)$. Recently several studies from different countries have reported colorectal carcinoma occurring in patients below 40 years of age $(4,5,6,7,8)$. It has been suggested that low survival in this young age group is due to more aggressive histological grades of tumour, low suspicion of malignancy in young people and delay in diagnosis (4). There is no documentation of the clinicopathological features of colorectal malignancies in young Sri Lankan patients. The objective of this study was to determine the clinicopathological features of colorectal malignancies in Sri Lankan patients aged $\mathbf{4 0}$ years or younger and to compare them with those of older patients.
Methods

The clinicopathological features of colorectal malignancies in 60 patients aged 40 years or younger and 245 patients aged over 40 years were analysed retrospectively. A total of 332 cases of colorectal carcinoma were available in the records of the University Department of Pathology, Colombo, for the 15-year period commencing from 1982. Twenty-seven cases were excluded due to non-availability of histology slides. All patients had been operated at the University Surgical Unit, National Hospital, Sri Lanka. The study population is not representative of the total number of patients with colorectal carcinoma operated at the University Surgical Unit during the 15-year period. Only the cases with histopathology records were studied because it was necessary to review the histology slides. The clinical features were obtained from information in the request forms and ward records. The clinicopathological features of patients aged 40 years or younger were compared with those of older patients using $\mathrm{X}^{2}$ test to assess significance between proportions. A p value $<0.05$ was considered significant.

\section{Results}

Sixty colorectal malignancies (19.67\%) occurred in patients aged 40 years or younger. The mean age was 34.3 (range 18 to 40 ) years. Of these, 2 patients were below 20 years of age. The numbers of patients in the 21-25, 26-30, $31-35$ and $36-40$ year age groups were respectively $3,9,14$ and 32. Their clinicopathological features are summarised in Tables 1 to 3. There were 37 males. The mean duration from onset of symptoms to diagnosis was 4.2 (range 2 to 7 ) months.

Table 1. Site of occurrence of colorectal malignancies

$\begin{array}{cc}\begin{array}{c}\text { Patients aged 4l years } \\ \text { or younger } \\ \text { or older } \\ n(\%)\end{array} & \begin{array}{c}\text { n } \\ 28(46.7)\end{array} \\ 4(6.7) & 101(41.2) \\ 3(5) & 57(23.3) \\ 1(1.6) & 13(5.3) \\ 5(8.3) & 7(2.9) \\ 2(3.3) & 16(6.5) \\ 3(5) & 1(0.4) \\ 7(11.7) & 17(6.9) \\ 7(11.7) & 19(7.8) \\ 60(100) & 14(5.7) \\ & 245(100)\end{array}$


Table 2. Presenting symptoms of colorectal malignancies in patients

\begin{tabular}{|c|c|c|}
\hline $40 y c$ & $\begin{array}{l}\text { irs and younger } \\
n(\%)\end{array}$ & $\begin{array}{c}41 \text { years and older } \\
n(\%)\end{array}$ \\
\hline Rectal bleeding & $19(31.6)$ & $58(25.7)$ \\
\hline Blood and mucus in stools & $12(20)$ & $25(11.1)$ \\
\hline Altered bowel habits & $12(20)$ & $59(26.1)$ \\
\hline Diarthoea & 0 & $12(5.3)$ \\
\hline Abdominal pain & $11(18.3)$ & $27(11.9)$ \\
\hline Abdominal mass & $4(6.7)$ & $11(4.9)$ \\
\hline Anorexia & $3(5)$ & $17(7.5)$ \\
\hline Weight loss & $3(5.0)$ & $17(7.5)$ \\
\hline Number of patients & $60 * * *$ & $226 * *$ \\
\hline
\end{tabular}

Table 3. Histology type and differentiation of colorectal malignancies

$\begin{array}{cc}40 \text { years and } & 41 \text { years and } \\ \text { younger } & \text { older } \\ n(\%) & n(\%)\end{array}$

Adenocarcinoma well

differentiated

$16(26.7)$

83 (33.9)

Adenocarcinoma moderately

differentiated

$23(38.3)$

Adenocarcinoma poorly

differentiated

Mucoid carcinoma **

Signet ring carcinoma

Carcinoid

Melanoma

Squamous cell carcinoma

Total

$\begin{array}{ll}8 & (13.3) \\ 8 & (13.3) \\ 3 & (5) \\ 1 & (1.7) \\ 1 & (1.7) \\ 0 & \\ 60 & (100)\end{array}$

$16(6.5)$

9 (3.7)

$5(2)$

$2(0.8)$

$245(100)$

** Statistically significant $(p=0.003)$

The percentage of patients aged 40 years or younger, who had Dukes' stage A, B, C, and D tumours were respectively $15 \%, 36.7 \%, 40 \%$ and $8.3 \%$. The percentage of older patients who had Dukes' stage A, B, C and D tumours were respectively $13.9 \%, 47.3 \%, 30.2 \%$ and $4.1 \%$. In this age group, in $4.5 \%$ of patients the Dukes' staging had not been done. There was no statistically significant difference between young and old patients in the presenting symptoms, site of tumour and Dukes' staging of colorectal malignancies. A statistically significant proportion of tumours in young patients, were mucoid (13.3\%) and signet ring cell $(5 \%)$ type $(\mathrm{p}=0.003) .3 .3 \%$ of young patients with colorectal carcinoma gave a family history of similar malignancy. A history of predisposing conditions (ulcerative colitis) was present in two (3.3\%) young patients.

\section{Discussion}

19.7\% of Sri Lankan patients with colorectal malignancies were $\mathbf{4 0}$ years of age or younger. This is similar to figures reported from Turkey (15.1\%), Ghana (17.9\%) and Saudi Arabia $(23 \%)(5,9,6)$. In developed countries the per- centage of young patients with colorectal malignancies is lower. The UK (10), Scotland (4), France (7), Sweden (11), New Zealand (6) and Japan (8) report respectively $2.5 \%$, $3 \%, 3.6 \%, 4.5 \%, 5,5 \%$ and $10 \%$. The high percentage in developing countries is probably not only due to the higher population of younger people in these countries. The 2 per 100000 incidence of colorectal carcinoma in patients below 40 years reported in the cancer registry, Maharagama (13) is higher than the incidences of 1.4 and 1.74 in Denmark (12) and Sweden (11) in people of similar age. The slight male predominance in our study is similar to studies in USA (14), Hong Kong (15) and Turkey (5). This contrasts with the equal sex distribution or slight female predominance in older patients $(2,9,16)$.

The presenting symptoms of young patients in our study were similar to those of other studies $(4,5,15,16,17,18)$ which have also not shown a statistically significant difference in the presenting symptoms of young and old patients $(4,11,12)$.

The proportion of patients in Duke stage $C$ and $D$ in our study were respectively $40 \%$ and $8.3 \%$. In other studies the proportion of Duke stage $\mathrm{C}$ tumours range from $16.7 \%$ (16) to $62 \%$ (5), while Duke stage D tumours range from $10 \%$ (5) to $70.8 \%$ (16). Widespread intra-abdominal and distant metastases are responsible for the poor prognosis of young patients with colorectal carcinoma (16).

In our study mucinous and signet ring cell carcinomas accounted for $13.3 \%$ and $5 \%$ of tumours in the young. This is similar to $18.8 \%$ mucinous tumours in young patients reported by Umpleby and Williamson (10) and $16 \%$ reported by Heys (4). The proportion of mucinous tumours was statistically significant when compared to older Sri Lankan patients ( $p=0.003)$. Studies in Saudi Arabia (6) and Japan (8) have reported similar results. Mucinous tumours are associated with an increased risk of local recurrence and reduction of overall survival $(17,19)$.

$3.3 \%$ of young patients in our study gave a family history of colorectal malignancies. This is similar to the 4.34\% reported by Heys in UK (4). In Turkey a family history of colorectal carcinoma was present in $14 \%$ of young patients (5). Two (3.3\%) of our young patients gave a history of ulcerative colitis. Other studies have reported predisposing factors to be present in proportions of young patients ranging from $4 \%$ in France (7) to $37.5 \%$ in Sweden (11). Survival data are not available in our study, as most patients were lost to follow up.

The symptoms of rectal bleeding, blood and mucus in the stools and alteration of bowel habits should lead to a suspicion of colorectal malignancy and appropriate investigation even if the patient is young.

\section{References}

1. Muir CS. Epidemiology, basic science and prevention of cancer implications for the future. Cancer Research 1990; 50: 6441-8.

2. Rosai J. Ackerman's surgical pathology. Volume 1. 8th ed. St. Louis: Mosby, 1996: 766.

3. Singh S, Morgan MBF, Broughton M, Caffarey S, Topham C Marks CG. A 10-year prospective audit of outconre of surgical treatment for colorectal carcinoma. British Journal of Surgery 1995; 82: 1486-90. 
4. Heys D, Sherif A, Bagley JS, Brittenden J, Smart C, Eremin O. Prognostic factors and survival of patients aged less than 45 years with colorectal cancer. British Journal of Surgery 1994; 81: 685-8.

5. Cicek Y, Tasci H, Gokdogan C. Ones S, Gazioglu E, Carkman S, Pekmezcis S. Colorectal cancer in patients younger than $\mathbf{4 0}$ years of age. Acta Chirugia Belgica 1993; 93: 258-61.

6. Isbister WH. Colorectal cancer below age 40 in the Kingdom of Saudi Arabia. Australian New Zealand Joumal of Surgery 1992; 62: 468-72.

7. Domergue J, Ismail M, Astre C, Saint-Aubert B, Joyeux H, Solassol C. Pujol H. Colorectal carcinoma in patients younger than 40 years of age. Montpellier Cancer Institute experience with 78 patients. Cancer 1988; 61: 835-40.

8. Okuno M, Ikehara T, Nagayama M, Sakamoto K, Kato $Y$, Umeyama K. Colorectal carcinoma in young adults. American Journal of Surgery 1987; 154: 264-8.

9. Naaeder SB, Archampong EQ. Cancer of the colon and rectum in Ghana: a 5-year prospective study. British Jourmal of Surgery 1994; 81: 456-9.

10. Umpleby HC, Williamson RC. Carcinoma of the large bowel in the first four decades. British Journal of Surgery 1984; 71: 272-7.
11. Ohman U. Colorectal carcinoma in patients less than 40 years of age. Diseases of Colon and Rectum 1982; 25: 209-14.

12. Bulow $S$. Colorectal cancer in patients less than 40 years of age in Denmark, 1943-1967. Diseases of Colon and Rectum 1980; 23: 327-36.

13. Cancer Registry: Cancer incidence in Sri Lanka 1990. Cancer Control Programme. 1996; 9-10.

14. Rao BN, Pratt CB, Fleming ID, Dilawari RA, Green AA, Austin BA. Colon carcinoma in children and adolescents. $A$ review of 30 cases. Cancer 1985; 55: 1322-6.

15. Van Langenberg A, Ong GB. Carcinoma of large bowel in the young. British Medical Joumal 1972; 3: 374-6.

16. Odone V, Change L, Caces J, George SL, Pratt CB. The natural history of colorectal carcinoma in adolescents. Cancer 1982; 49: 1716-20.

17. Mills SE, Allen MS Jr. Colorectal carcinoma in the first three decades of life. American Journal of Surgical Pathology 1979; 3: 443-8.

18. Smith C, Butler JA. Colorectal carcinoma in patients younger than 40 years of age. Diseases of Colon and Rectum. 1989; 32: 843-6.

19. Behbehani A, Sakawa M, Erlichman R. Colorectal carcinoma in patients under age 40. Annals of Surgery 1985; 202: 610-4. 